\title{
El Concepto de Educabilidad y el Proceso Educacional
}

\author{
JOAQUÍN GARCÍA CARRASCO \\ Universidad de Salamanca
}

\begin{abstract}
SUMMARY.-The concept of educatability is reconsidered in this article. Instead of analysing it as a property of the structure itself or as a property of man, before all other considerations it may be understood as the opportunity that arises from the transaction between the individual and his/her environment. At the same time the primary mechanisms of the constitution of the opportunity of modifying man's behaviour are posed, taking into consideration the three major vectors by which the system of behaviours constituting a human being's personality has, on principle and from the very beginning, been affected: developmental processes, transactional processes and cultural processes.
\end{abstract}

\section{EL MARCO O ENCUADRE DE LA EDUCACIÓN}

Carlo Cipola ${ }^{1}$ termina un libro precioso donde estudia las relaciones entre el desarrollo de los roles e instituciones docentes con un párrafo sin desperdicio:

\begin{abstract}
«Cuando, mucho tiempo atrás, los maestros enseñaban a leer y a escribir, también se preocupaban de los posibles usos de esta técnica. Desgraciadamente, estas preocupaciones tomaron formas de santurronería religiosa o política, pero esto no significa que el problema fuese irrelevante o falso. Todos los que enseñamos técnicas tenemos que enseñar también las implicaciones éticas de sus usos alternativos. Instruir a un salvaje en las técnicas más avanzadas no supone hacer de él una persona civilizada, sino un salvaje más eficiente. Si la vida en este planeta nació y se desarrolló gracias a procesos independientes de una voluntad consciente, éste ya no es el caso en un mundo industrialmente avanzado en el cual el hombre domina fuerzas cada vez más poderosas.

En el futuro, la vida sobre la tierra dependerá, cada vez más, de la capacidad del hombre para 'perseguir la virtud' más que el 'conocimiento'».
\end{abstract}

En definitiva, Cipola lo que afirma es que el futuro del entorno vital que hace posible una vida con significado para el hombre está en dependencia de la orientación que el hombre dé a las aspiraciones que persigue. De tal orientación depende la felicidad colectiva e incluso la permanencia de la vida en la Tierra. Desde que el hombre aparece, la permanencia de la biodiversidad es cuestión de iniciativas humanas, no queda más que un paso para poder afirmar que la continuidad de las posibilidades vitales humanas es,

1. Cipola, Carlo (1969), Educación y desarrollo en occidente (Ed. Ariel, Barcelona) p. 136. 
en general, un problema de educación, y la educación es calidad en la conducta, valor de conducta.

Ello quiere decir que los fenómenos educacionales, aunque siempre impliquen actividad cortical y procesos cognitivos, no se reducen a la categoría de estos fenómenos propios de los procesos de enseñanza-aprendizaje, de contenidos informativos de naturaleza proposicional. Hay otras categorías de comportamientos, actitudes, normas..., que aunque pueden ser descritas o enunciadas proposicionalmente, no se «consiguen» por esa vía exclusiva.

Sería un error muy grave deducir de la afirmación general de que la calidad de vida, el equilibrio de la personalidad, la evitación de huidas hacia la drogodependencia, el progreso social..., se encuentran asociados a calidad de procesos educacionales, que tales objetivos constituyen un problema educativo inmediatamente alcanzable a través de un diseño pedagógico; $y$, por lo mismo, una responsabilidad profesional de los agentes sociales que llamamos educadores, profesores, pedagogos... Eso es lo mismo que afirmar que las categorías de las acciones pedagógicas y las de las acciones educativas no son convertibles, que no todo proceso educacional puede ser reconstruido pedagógicamente.

\section{Dimensiones o estratos en el fenómeno educacional}

Si sintetizamos grandes dimensiones o perspectivas en los procesos educacionales, habremos de reconocer -tanto por observación a primera vista, como por tradición científica, como por documentación bibliográfica- que en lo que denominamos educación quedan comprometidos:

(i) estados y procesos mentales (tanto puramente cognitivos, como afectivos, como perceptivo-motóricos), muchos de los cuales se pretenden favorecer psicopedagógicamente y optimizar (sacarles partido);

(ii) estados y procesos de recepción y manipulación de material simbólico valorados personal y socialmente, respecto a los cuales se interviene, en parte, mediante la planificación de secuencias curriculares o el planteamiento de políticas culturales que inspiren y dirijan procesos más difusos de dinamización cultural ${ }^{2}$;

(iii) acciones y procesos de interacción y participación social los cuales se estimulan e inducen creando situaciones, componiendo escenarios e institucionalizando las condiciones que permitan el ejercicio de las competencias y roles de los individuos dentro del sistema social ${ }^{3}$.

En el estado de cosas de la educación de los individuos y de los grupos humanos, tomado en su conjunto, confluyen la dinámica evolutiva de la humanidad (proporcionando contextos culturales, sistemas simbólicos, concepciones del mundo...), los procesos evolutivos de los sujetos particulares dentro de las instituciones sociales primarias y las resultancias de los productos culturales que se continen en los flujos de comunicación y en los medios de comunicación, en los sistemas de producción, y en las relaciones de producción, y en todo el tejido institucional y relaciones sociales.

2. Un problema didáctico interesante es el que plantea la obra siguiente: Zárate, G. (1986), Comment enseigner une culture étrangère (Hachette, Paris).

3. García Carrasco, J. (1992), «La perspectiva ecológica y el discursos teórico de la educación», en Rv. Teoría de la Educación, vol. IV, pp. 53-72. 


\section{Las imágenes mentales y la fragmentación del fenómeno educacional}

Las imágenes mentales explican, en parte, el discurso intelectual sobre los fenómenos estudiados. Las imágenes preponderantes sobre la educación se componen desde un criterio de fragmentación.

Nuestra percepción sensorial, tal y como se anida en las palabras ha entendido los fenómenos educacionales fundamentalmente como procesos de influencias que tenían como soporte la comunicación: verbal por las enseñanzas (instrucciones, consejos, órdenes...) y no verbal por los ejemplos/modelos, exhibición de sistemas de comportamientos. De tal suerte que si excluyéramos de los elementos que componen la visión habitual de los fenómenos educativos el elemento magistral/educador, físicamente contenido en personas y roles, vaciaríamos el discurso y nos quedaríamos sin realidad a primera vista. En esta primera visión el ambiente es mero escenario.

El espacio social original de la relación pedagógica ha sido el espacio familiar (trama de parentesco), el espacio de intervención entre iguales (trama sociotélica), y el espacio de cooperación social orientado a la supervivencia del grupo (trama orgánica social).

\section{COMPORTAMIENTO Y RELACIÓN CON EL ENTORNO}

«La conducta incluye todos aquellos procesos a través de los cuales un animal percibe el mundo externo y el estado interno de su cuerpo, y responde a las variaciones que percibe» ${ }^{4}$, aunque el conductismo restringiera el significado. En esta definición de Manning quedan de relieve dos aspectos esenciales del comportamiento: la receptividad de informaciones y la expresividad en las manifestaciones, si bien no se reflejan los procesos internos de elaboración con ello conectado. Se quiere indicar, en principio, que en cada especie animal el campo de percepción en cuanto a espectro sensorial y en cuanto a capacidad de interpretación de indicios de significado y el espectro de manifestación en cuanto a categorías de mensajes emitidos serán elementos definitorios de la especie. Esto es precisamente lo que ha puesto de relieve la Etología.

\section{Construcción de significado}

El comportamiento del hombre no queda orientado meramente a la sobrevivencia, sino que el vivir humano es la permanente persecución o exclusión de «mundos posibles».

Esta capacidad de creación de significado y de creación de posibilidades se encuentra conectada al modo como se relaciona el hombre con su entorno físico, biológico y social: no aparece como mera capacidad de satisfacción de necesidades vitales, sino que aparece «en realidad» y ello contiene lo que es y el potencial de constructo y de realidad inventada a que se hace susceptible. El mundo aparece en la historia humana como un 
campo de realidades que paulatinamente comprende y un campo de posibilidades que continuamente busca «hacer reales», o de las que se propone huir. Todo ello es lo mismo que afirmar que la historia humana es el proceso y el relato de la transformación de la naturaleza en cultura.

La orientación de la cultura no depende únicamente del éxito evolutivo de una capacidad comportamental en un entorno determinado, sino de cuestiones ligadas al «aprecio-menosprecio», a categorías de valor; y, en el fondo, a criterio moral.

Una teoría de la plasticidad del comportamiento humano ha de tomar en cuenta las lecciones que proporcionan los procesos de evolución que constituyeron la estructura que soporta su actividad mental y las que proporcionan los procesos de su actividad psíquica, entre los que se encuentran, precisamente la posibilidad de elaborar comportamiento y la posibilidad de influenciar comportamiento. La elaboración y construcción de comportamiento la expresa el concepto de educación, la interacción que influencia e induce comportamiento la expresa la función de educar.

\section{LA EDUCABILIDAD HUMANA}

\section{A. La modulación de las especies en la evolución}

En el lenguaje conversacional y en la literatura pedagógica el concpeto educabilidad se atribuye con exclusividad al hombre. Sin embargo, su aparición como cualidad del ser humano es fruto de los procesos que han tenido lugar durante la evolución; el código genético, entendido como sistema regulativo, contiene tal posibilidad y la de que realmente puedan tener lugar los procesos educativos en transacción o interacción con el ambiente y a través de mediaciones sociales; si no fuéramos como somos ésto no sería posible. Entre los procesos educativos y los evolutivos se dan, sin embargo, diferencias radicales. Los segundos se transforman en hechos evolutivos en las sucesivas generaciones, no son propiamente acontecimientos individuales sino de poblaciones, el éxito de los mismos no estriba en influencia sobre un organismo sino en el éxito reproductivo ( está necesariamente conectada la reproducción, y la memoria del cambio queda cifrada en el código genético. La educación es un acontecimiento individual sin huella en el código genético, aunque las propiedades orgánicas que la hacen posible estén genéticamente determinadas, los cambios originados son comportamentales y no orgánicos aunque tengan consecuencias orgánicas, la acumulación de las posibilidades educativas pertenecen al patrimonio social y no al individual. En ocasiones, se atribuyen los éxitos educacionales a condicionamientos hereditarios, a genética y no a justicia distributiva, de ahí la importancia del estudio del papel de la evolución, y como consecuencia la del estudio del sustrato orgánico de los procesos educacionales.

En sentido general evolución es el proceso de cambio de los seres vivos a través de sucesivas generaciones. Los cambios graduales en los organismos afectan a su apariencia, a su estructura morfológica y fisiológica, a su comportamiento en el ambiente (fenotipo), y a su dotación genética (genotipo). Los cambios fenotípicos, estructurales o comportamentales no tienen consecuencias evolutivas, si no se sustentan en modificaciones genéticas. Nada que tenga, pues, propiamente la condición de adquirido se incorpora 
al código genético. La educación por lo tanto no es propiamente un acontecimiento evolutivo. La noción de herencia cultural deberá ser explicada.

Genotipo y fenotipo se contraponen como se contrapone la información y la configuración. Genotipo es información, instrucciones sobre procesos y regulaciones de los mismos. El fenotipo es la configuración final del organismo como consecuencia de las informaciones genéticas y de la regulación de las relaciones entre el individuo y sus circunstancias ambientales. El genotipo transmite información genética e información evolutiva; es decir, información sobre estructura e información sobre desarrollo de la misma en el tiempo.

En el concepto de evolución se contienen tres elementos: (i) Hechos evolutivos, o el hecho de la evolución, (ii) el proceso de la evolución y sus etapas reales, (iii) los mecanismos mediante los cuales tiene lugar. Mientras los dos primeros tienen una comprobación directa, el tercero tiene naturaleza inferencial y es propiamente un constructo teórico: la teoría de la evolución. Los tres forman parte de la demostración del carácter cambiante de la naturaleza de los seres vivos y de la del hombre mismo.

En la teoría de la evolución aparecen tres tipos de proposiciones: (i) aquellas que establecen que los organismos se encuentran emparentados a través de antepasados comunes, (ii) las que proponen la historia evolutiva de los organismos en particular, (iii) y las que se refieren a los mecanismos evolutivos que lo hacen posible.

\section{La evolución y el hombre}

El ser humano es un ser evolutivo porque se dan en él las dos condiciones fundamentales de la evolución: diversidad genética intraespecífica y diversidad y cambios en las condiciones ambientales.

En el hombre la evolución tiene dos aspectos claramente diferenciables: la variación biológica y la variación cultural. Ambas se encuentran interaccionadas. La cultura desarrolla y amplifica los procesos de satisfacción de necesidades, por otro lado la cultura desarrolla el poder adaptativo de la naturaleza biológica.

La herencia biológica se organiza con los mismos elementos que el resto de los seres vivos. La herencia cultural humana introduce procesos nuevos, unos prefigurados en los animales (la imitación), y otros específicos como la enseñanza o la creación de una tupida red de sistemas de comunicación y de transferencia de información. Los artefactos de los animales son vitalmente interesantes, el hombre ha creado la industria cultural. La cultura es un mecanismo de adaptación más eficaz y poderoso que los procesos biológicos. Más poderoso porque no requiere numerosas generaciones para introducir en una población un patrón de comportamiento. Sobre todo, introduce un proceso de modificación del ambiente para potenciar la adaptabilidad. Es probable que la mutación genética de la humanidad esté aumentando por diversos motivos: mortalidad diferencial mitigada como consecuencia de los conocimientos médicos, fertilidad diferencial mitigada como consecuencia de la igualdad social o de principios éticos o religiosos.

\section{El hecho cultural}

El desarrollo tecnológico vinculado a configuraciones comportamentales de sobrevivencia sufre un movimiento de cambio radical en cuanto a la rapidez de evolución en pleno florecimiento del Homo sapiens. Dos razones de la rapidez de la evolución cultu- 
ral son: (i) sus cambios y modificaciones no dependen del azar, sino del propio interés que despierta el desarrollo y complejidad de la tecnología, (ii) la transmisión de estos patrones no depende de los gametos sino de la información transmitida por un ser adulto. La cultura no progresa por azar, sino como camino hacia la solución más ventajosa o perfecta o preferida de un problema.

\section{Mecanismos de la modulación morfológica en el hombre}

Para Faustino Cordón los mecanismos que han llevado a una modelación morfológica y etológica de esta envergadura son, en línea de mayor y en trazos gruesos, los que obedecen a los siguientes principios hipotéticos, corroborados convergentemente por la paleontología animal:

(i) El enfrentamiento irreversible con un medio diferente al propio de la especie. El término «medio ambiente», para muchas personas, no contiene más referencias que la idea de paisaje. Sin embargo, el medio de una especie animal está constituido básicamente por las demás especies animales con las que se encuentra en relación regular, con las que compite y con las que son sus genuinos depredadores.

La entrada en un medio nuevo al que inicialmente se encuentra desadaptado, solamente se puede compensar para la sobrevivencia, con la mejora de la capacidad congénita de tomar noticias del exterior y seleccionar las respuestas más adecuadas: nueva configuración o un mayor desarrollo nervioso. Este principio constituye un enunciado normativo de carácter general, cuyo valor incluso reconoce el lenguaje coloquial. En la historia de la cultura se ha considerado enriquecedor «el viaje», la salida del entorno para conocer nuevos mundos y pueblos, el contacto con otras culturas; en definitiva enuncia el principio pedagógico de enriquecimiento comportamental como consecuencia de la expansión del medio activo influyente. Un mecanismo espontáneo de reserva y protección de los propios patrones culturales consiste en el inverso de selección de los contactos, filtración de los interlocutores, evitación de ambientes. La mayor cristalización de un patrón cultural, de cualquier tipo -incluido el consumo de droga y las conductas antisociales- se da en los miembros nucleares y consolidados de los grupos, la mayor labilidad y posibilidad de cambio en los miembros más periféricos y abiertos hacia el exterior. De ahí que la impermeabilidad social a la relación con grupos marginados, al tiempo que protege a unos de posibles influencias, actúa como mecanismo de consolidación de patrones radicalizando la marginación. En todos los movimientos de cambios sociales, movilidad de personas en territorios, incluso estabilidad social..., el proceso de armonización social pasa por iniciativas de integración. La integración contiene en sí misma una dinámica de hacia fuera: salir de los propios encuadres culturales ya sea mediante aceptación de otros en el propio marco convivencial, o de salida y contactos con otros encuadres diferentes a aquellos en los que tuvo lugar la disfuncionalidad. La palabra integración es la clave expresiva pedagógica respecto a grupos de disminuidos, grupos étnicos, grupos marginales... Entre los factores de integración dominantes se encuentra, pues, la movilidad mediante la que se insertan los individuos en nuevos entornos; instrumentalmente, las vías de comunicación y los sistemas de comunicación siguen constituyendo un mecanismo básico para la modulación de los patrones culturales. 
(ii) El segundo principio rector del proceso es el siguiente: En las características originarias de las relaciones entre individuo y medio no se da una situación edémica jamás. El reino animal es el de la más rigurosa y extrema necesidad, propendiente a la saturación y a la selectividad en la utilización energética. Dramáticamente se consigue el equilibrio ecológico entre especies. El hombre fue el animal que evolutivamente rompió el equilibrio entre especies; es decir, se emancipó de la dependencia exclusiva respecto a la reserva estricta de un determinado tipo de alimento; del hábito alimentario dependen las demás especies, y con respecto a él, perfeccionan la manera de conseguirlo; es decir, su explotación especializada.

Cada conquista comportamental multiplica la complejidad ambiental activa y la versatilidad del medio útil, acelera el tempo de transformación etológica del grupo y, como dijimos antes, rompe los cánones mediante los cuales se definen las posibilidades vitales de una especie animal.

Este segundo principio advierte que todo proceso de movilidad de entornos y, por lo mismo, todo proceso de modificación de encuadres culturales conlleva conflictos, dado que rompe los equilibrios socioculturales establecidos en los que los sujetos encontraban seguridad. Tales conflictos se manifiestan en forma de miedo a lo extraño, temor al extranjero, desconfianza sobre veracidad de actitudes, temor a la influencia nociva, suspicacia por la pérdida de privilegios establecidos...; manifestaciones típicas de todas las iniciativas de integración social. Junto a ello el riesgo a la pérdida de identidad.

\section{La liberación ecológica}

Todo parece dar a entender que el hombre se ha liberado de la dependencia de su nicho ecológico mediante la transformación de la dependencia en un sistema de cultura, lo que es una nueva forma construida de dependencia; en adelante todo parece -en algunas ideologías- indicar que tanto la educación como la prosperidad individual y colectiva podrá llevarse a cabo de espaldas a la tierra, y sin el menor riesgo para la sobrevivencia.

Desde este punto de vista la educación no sería otra cosa, tomada en su conjunto, que el equipamiento humano para el dominio del hombre sobre la naturaleza, la liberación ecológica, según la define Rodríguez Delgado ${ }^{5}$. Mediante la técnica el hombre ha adaptado su entorno activo influyente más próximo, su vivienda y el medio en el que se encuentran los elementos básicos de su cadena trófica, de forma tal que ha podido conquistar los espacios más inhóspitos y ha creado toda una cultura alimentaria y de transacción de alimentos. Ideológicamente pasó al concepto de dominación ecológica, «victoria de la inteligencia sobre la naturaleza acéfala».

Este planteamiento no reconoce, sin embargo, ni la condición etológica del hombre en el mundo, ni la dependencia al entorno. La educabilidad, ese limitado margen de configuración de comportamientos en el mundo que posee el hombre, se concreta y define en virtud de creencias y concepciones, en vez de restringirse en virtud de sistemas de patrones más o menos rígidos. Pero del hecho de que la rigidez y determinación genética del comportamiento se haya en buena medida, y en algunos sentidos, superado no se

5. Rodríguez Delgado, J. M. (1972), Control físico de la mente, hacia una sociedad psicocivilizada (Ed. Espasa Calpe, Madrid). 
sigue que el sentido de la educación no siga siendo el de la transacción ordenada de las relaciones entre el individuo y su entorno en vistas a la sobrevivencia compartida de la especie en su medio. Ni siquiera el hombre puede sobrevivir a su entorno. La educabilidad es el intervalo de opciones sobrevivenciales que se corresponden a la desespecialización del comportamiento humano en la tierra; con una gran restricción: que son muchas las opciones que llevan a la destrucción del medio, al deterioro individual y colectivo. Donde las relaciones entre el organismo y el medio estaban regidas por los mecanismos que hemos descrito, ahora, con el hombre, esas relaciones han de quedar regidas por la razón práctica.

A fuerza de entender la educación o repleción de las opciones del sistema comportamental como consecuencia de la acción de un hombre sobre un niño, se ha impedido/perdido (que el labriego mira mucho al cielo y a la tierra) la visión de la parte que en la repleción sigue correspondiendo a las relaciones individuo-medio, aunque éste sea medio culturalmente construido. Tal pulsión transaccional con el entorno no puede ser sustituida o reorientada, sino parcialmente, por sistemas alternativos de configuración e intencionalidad del comportamiento, como la educación intelectual o moral.

\section{B. Modulabilidad de la mente y de la actividad mental}

\section{El órgano de la mente}

El primer elemento de maleabilidad lo hemos encontrado en la evolución misma de las especies. El segundo eje de la maleabilidad lo encontramos en la mente. No es una maleabilidad independiente de las relaciones con el entorno, sino consiguiente a la misma. Esta maleabilidad se encuentra asociada a la complejidad suma. Tres serán los problemas que vamos a estudiar: (a) La complejidad de la estructura en la que tiene lugar la actividad mental, entendiendo por ella no solamente la propiamente intelectual o de procesamiento de la información, sino también la afectiva y la psicomotórica; (b) la modularidad de la mente; (c) las relaciones entre actividad mental y estructura corporal.

\section{Marco de referencia}

Los comportamientos individuales, de cualquier naturaleza, no existen en sí mismos sino que son consecuencia de la actividad funcional del organismo como un todo, o de alguno de sus subsistemas en particular. En concreto las conductas a las que se refiere la reflexión pedagógica son producidas y controladas por el Sistema Nervioso Central (SNC). Este sistema, como cualquier otro, posee: (i) una composición o conjunto de elementos definibles/diferenciables en el mismo, (ii) un entorno o conjunto de elementos, que sin formar parte del mismo influencian, son influidos o mutuamente interactúan; (iii) una estructura o conjunto de relaciones de todo orden entre los elementos del sistema o del sistema con los componentes del entorno; (iv) todo sistema posee propiedades emergentes que no pertenecen a los elementos individualmente considerados, ni a alguno de sus subistemas. A los valores, no tienen por qué ser cuantificables, de las propiedades del sistema dentro de un ámbito de variabilidad, en un momento dado, se denomina es- 
tado del sistema. El conjunto de todos los estados posibles del mismo constituye el espacio de estados del sistema. Gusto/disgusto, agrado/desagrado, atención/desatención, aprecio/menosprecio... son estados y valores «binarios» o polares.

En el discurso pedagógico, a veces, arrastrado por una tradición cultural, aparece el organismo y la mente como si se tratara de sistemas diferentes; consecuentemente se establecerían dos espacios de estados en el individuo; en concreto, uno para los del SNC y otro para los de la mente. Nosotros defendemos el punto de vista de que todos los comportamientos humanos son el producto de funciones cerebrales. Lo cual no impide que el conjunto de comportamientos del individuo no pueda a su vez ser definido como un sistema, el sistema de comportamiento de propiedades y características no reducibles a fisiología. El comportamiento contiene todos los elementos de la definición de sistema, de la misma manera que los cumple también una teoría científica, pero tal teoría se entiende como producto de las funciones cerebrales del individuo y no de otra entidad a la que llamáramos mente; igualmente ocurre con la noción de sistema simbólico.

Puesto que la condición de sistema activo no se consigue por mera aproximación o yuxtaposición de elementos es conveniente atender las causas de la aparición de los elementos y las causas por las que se extienden las relaciones o el perfeccionamiento de las funciones. Las conexiones iniciales entre neuronas y el establecimiento de los circuitos básicos habrán de ser determinados por los genes. De hecho, incluso antes de nacer ya se dan comportamientos anticipatorios (movimientos de succión, contracciones pectorales prerrespiratorias...). Hoy sabemos que la actividad neuronal, concretamente el potencial de acción, es esencial para el desarrollo de la neurona. Si se impide, a neuronas en desarrollo, la transmisión de potenciales de acción, los sacos terminales del axon se detienen en un estado inmaduro: no crecen, no establecen sinapsis nuevas. En determinadas estructuras del sistema, llegado un cierto punto, se detiene el proceso diferenciador, deteniendo su plasticidad; tal es el caso de vías sensoriales principales. Pero en otros casos, el mantenimiento de la capacidad de modificación es esencial, como en el caso de los sistemas responsables del aprendizaje. Ese período temporal de plasticidad de los sistemas es lo que se denomina períodos críticos. Ese mismo potencial que funciona como una señal, constituye una actividad fundamental para el propio desarrollo del cerebro. La ausencia total de potencial de acción se consiguió bloqueando el sistema mediante la inyección en retina de tetrodotoxina, en esos casos se demostró que el potencial de acción era necesario para la formación de sinapsis y para la formación de columnas visuales específicas; su ausencia, detenía el proceso de maduración de los sacos axónicos en las células ganglionares.

Generalizando el planteamiento se puede estimar que la mejora de la estimulación en los sistemas con plasticidad depende de la propia actividad del sistema. Es decir, la educabilidad de un sistema flexible no es una propiedad intrínseca del sistema, sino una propiedad emergente de la naturaleza de su estructura funcional y de la activación del mismo a partir de la experiencia. Por decirlo de manera más paradójica, la educabilidad es la propiedad que aparece en el sistema mental humano, cuando este sistema se educa; la inversa no sería cierta. Tal planteamiento explica las consecuencias antropológicas del abandono. Pero, tampoco la educabilidad sería completamente descrita como propiedad emergente de la transacción entre el hombre y el mundo; hay que hablar de estar activo en el mundo de las cosas y de los hombres; dando a entender que la socialización y la internalización del patrimonio cultural es igualmente importante que la es- 
timulación directa que nos proporcionan las cosas del mundo: todo eso es lo que compone nuestro mundo.

El progreso en la educabilidad está en relación con la experiencia, ya que la actividad de la mente no consiste únicamente en percibir o recibir estímulos; almacena indicios, categorías de estimulación que favorecen el reconocimiento. Alkon afirma que en ese sentido «el ser humano es un dispositivo reconocedor de patrones, creado en el transcurso de la evolución; las memorias son los patrones que se almacenan» ${ }^{6}$.

Esto permite inferir que el proceso de educabilidad, el cual es un proceso no original, sino subsiguiente a la experiencia, no es un potencial abierto sino condicionado al sistema de patrones almacenado; son ellos los que determinan los márgenes de nuevos campos de experiencia posible. Por lo mismo, junto al planteamiento de la educabilidad se encuentra intrínsecamente asociado al planteamiento de los límites. En contra de ciertas reflexiones educativas que atribuyen a cada hombre, en cada momento y lugar, un potencial de educabilidad ilimitado.

De tales afirmaciones se infieren otros principios básicos de los procesos originales: la calidad y contenido de las experiencias constituyen un determinante de la educabilidad posible, dentro de las limitaciones que pueda determinar el código genético. La calidad de experiencia que ofrezca el entorno de influencias es un factor constituyente de los márgenes de educabilidad y de la orientación del sistema de comportamiento. Un criterio, fundamental, para el cambio de la modulación del sistema de comportamiento es el de proporcionar nuevos espacios de experiencia. Cosa que no podrá llevarse a cabo, sin tener en cuenta los principios establecidos en el apartado anterior. Explica igualmente que uno de los derechos fundamentales del hombre se exprese en forma de derecho a la educación o derecho a igualdad de oportunidades ante la educación, es como reclamar oportunidades de experiencia. En la medida en que el comportamiento se encuentre mayormente en fase de elaboración, las urdimbres experienciales mediante las cuales se activa el sistema nervioso, constituirán de manera más decisiva el sistema de personalidad de los individuos. Esto es lo que afirma y comprueba la importancia de los primeros estadios infantiles, dentro de la unidad familiar, en los que incluso la proximidad física y el contacto cuerpo a cuerpo se constituyen en indicios de integración. Algunos de los complejos de la estructura comportamental humana, actitudes, normas morales, no se configuran o internalizan por otros procedimientos que no sean la creación de espacios experienciales; en ellos la enseñanza, o la argumentación es menos eficaz.

Dado el sistema comportamental y la estructura del mismo, el contenido de la acción, el valor de la acción, la educación, se desarrolla con la propia actividad, y el patrón que la actividad genera define el margen de la educabilidad. Con el mismo cerebro, durante los primeros 2.500 .000 años la relación entre el hombre y el entorno, según los restos paleoantropológicos, estuvo regida por patrones de reconocimiento vital (patrones conectados a la actividad sobrevivencial) y por patrones utilitarios. Hace aproximadamente 35.000 años aparecen los primeros patrones simbólicos (adornos del cuerpo y representaciones naturales en dos y tres dimensiones en la época auriñaciense), lo que representa innovaciones en la actividad y progreso en el dominio cultural de la imaginación espacial y visual; a su vez permite percatarse de un amplio espectro de posibilida-

6. Alkon, D. L. (1989), «Almacenamiento de memoria y sistemas neurales», en Rv. Investigación y Ciencia, septiembre, pp. 14 ss. 
des sociales, tecnológicas y míticas ${ }^{7}$. La educación sensorial y la influencia sobre la actividad corporal se manifiestan como actividades básicas o primarias del proceso educacional.

\section{Educabilidad y plasticidad}

Plasticidad es «la capacidad que tiene el SNC de cambiar su composición o su organización (estructura) y, en consecuencia, de modificar algunas de sus funciones (actividades) incluso en presencia de un medio (aproximadamente) constante ${ }^{8}$. Esta plasticidad es una expresión del diseño genético (sólo se observa en el reino animal y de manera más sorprendente en los animales superiores) y de las transacciones ecológicas. Desde un punto de vista funcional la plasticidad es la capacidad de adaptar y modificar el comportamiento a los cambios ambientales y la de explorar y modificar el medio en función de intereses vitales o de necesidades culturales. La plasticidad de la mente se encuentra asociada a la posibilidad de elaborar representaciones ambientales y a la de elaborar planes de acción. Son correlativas la complejidad de la estructura neuronal actuante y la complejidad del esquema de acción posible; y esto tanto a lo largo de la evolución (filogénesis) como a lo largo del desarrollo del animal (ontogénesis). La educabilidad es la consecuencia de la plasticidad del SNC en el hombre.

El margen de plasticidad en el hombre es inmenso. Cualquier definición de aprendizaje o de modulación del comportamiento, en este nivel de consideración, se encuentra relacionado con la conectividad (en sinapsis, pero sin olvidar que el cuerpo de la neurona no es espacio vacío para la conectividad) de algún/algunos sistemas neurales y con cierta medida de compromiso en los mismos; el uso de la conectividad la refuerza, el desuso la debilita y el margen de conectividad (creatividad) permanente es inmenso. De ello deducimos otro principio básico de los procesos educacionales en el hombre. Los márgenes de educación posible se encuentran asociados a la propia actividad permanente del sistema: las posibilidades de educación del hombre están en dependencia de su educación permanente, la disminución de oportunidades de educación permanente disminuyen las posibilidades de educación. Cuando hablamos de educación para la crítica o de la apertura cultural, no indicamos otra cosa primariamente que la creación de escenarios de educación permanente y de alerta cultural constante. Escenarios en los que se relaje esa alerta o la incentivación de la misma no pueden exigir o concebirse a sí mismos como planificaciones de modificación comportamental o procedimientos de adaptación o integración cultural.

En la base de todo proceso educativo se encuentra la hipótesis o teoría que M. Bunge denomina de la identidad psiconeural o hipótesis psicobiológica de lo mental: los estados mentales son idénticos a sucesos cerebrales; las propiedades de esos sucesos mentales-neurales son propiedades de los sistemas y no resultantes de la mera actividad bioquímica que acontece en las neuronas individuales. Pero no toda actividad cerebral es

7. White, R. (1989), «El pensamiento visual en la edad del hielo», en Rv. Investigación y Ciencia, septiembre, pp. 64 ss.

8. Paillard, J. (1976), «Reflexions sur l'usage du concept de plasticité en neurobiologie», en $J$. Psychologie, 73, pp. 33-47. 
actividad mental, únicamente la de aquellos sistemas neurales que no se encuentran comprometidos, es decir, que son plásticos; correlativamente diremos que todo desorden mental es un desorden neural; lo cual no significa que para todo desorden mental podamos construir un mecanismo bioquímico de reestructuración. Es perfectamente compatible el hecho observado que frente a determinados desórdenes mentales podamos actuar mediante la inducción de procesos mentales y no meramente de fármacos, de alguna manera «volviendo a aprender». Este volver a aprender, desde el fondo, es el principio que parece contener la «primera etapa» que se propone en la Asociación de Alcohólicos Anónimos. Y manifiesta, igualmente, la dificultad de reinserción de individuos disfuncionales socialmente: han de reestructurar su experiencia vital.

La metáfora dominante en muchos medios psicopedagógicos es la del ordenador, en tanto que máquina que procesa información, y el modelo input-output como categoría de procesamiento de la información. El hecho de la existencia de actividad excitatoria interna y, sobre todo la actividad inhibitoria, mantiene el valor heurístico de la imagen pero la invalida como modelo explicativo.

Pretender que el fenómeno educativo humano se encuentre reducido a procesos de influencia (estimulación, comunicación) en los que intencionalmente intervienen ciertos protagonistas es tomar el todo por la parte. Pero también hay que advertir, recordar, que el SNC no madura estructuralmente ni se desarrolla funcionalmente sin la transacción con el entorno. Las polarizaciones agente-paciente son absolutamente inadecuadas. El hombre y los animales son esencialmente activos; no sólo en lo referente a sus relaciones con el medio externo, sino incluso en lo que se refiere al medio interno. Los sujetos pueden aprender a controlar sus emociones, a controlar su ritmo respiratorio o, incluso, incrementar las «ganas de vivir» frente a los efectos humorales lógicos como consecuencias de estados de enfermedad graves (p. e. estabilidad emocional e ideacional en enfermos terminales, o desactivación parcial de los centros del dolor mediante entrenamiento mental). No cualquier entorno es suficiente, sino aquél que es ecológicamente apropiado a su especie y apropiado a los objetivos culturales: el mundo de las cosas y de los hombres.

\section{Límites de la actividad mental}

En algunos libros de Pedagogía hay capítulos titulados así: Los límites de la educación, o del perfeccionamiento humano. Se señalan la «herencia, la sociedad, la cultura». Así dicho no se adivina donde está la idea de límite. El proceso de elaboración de comportamientos en el hombre se encuentra limitado estructuralmente, en el sentido de que el límite se origina en el propio modo de ser del organismo con capacidad mental.

\section{Capacidad limitada de los sistemas sensoperceptivos}

Lo más destacable son las limitaciones que imponen las estructuras de los sistemas periféricos de entrada y los sistemas neurales anexos a la captación de datos. Esta es una limitación cualitativa, porque no para todas las perturbaciones físicas externas disponemos de receptores. Aun así pueden esas perturbaciones producir efectos biológicos en el organismo; estos efectos puede la mente asociarlos a la percepción de signos ambienta- 
les, aunque no posea receptor para la perturbación. Tal ocurre con los ultrasonidos, la luz ultravioleta, la radiación electromagnética... Se dan limitaciones cuantitativas desde el momento en que los receptores solamente actúan dentro de un determinado intervalo del que se ocupa, para cada receptor, la psicofísica. Otras limitaciones son topográficas dependiendo de la orientación del organismo en el espacio (no vemos lo que hay a nuestra espalda). La limitación más importante depende de la propia capacidad de tratamiento de la información propia del sistema. Es algo que en el lenguaje conversacional se expresa en forma de «no puedo abarcar», «no puede atender al mismo tiempo»... Y también en la práctica pedagógica de «dosificación de la información»...

En respuesta a estas limitaciones el organismo reacciona planteando estrategias. La limitación de capacidad en las entradas se responde con la atención. A los rasgos de los objetos estimuladores capaces de activar la atención selectiva del organismo, los llamó Pieron «proxesígenos». Algunos de ellos son: intensidad física, novedad, valor biológico, valor social... Una segunda estrategia es la de organizar los elementos percibidos en paquetes con sentido; principio en el que se funda la organización por esquemas y agrupamientos de los materiales que se estudian o el aislamiento de organizadores de la información y conceptos clave.

\section{Selectividad y limitación en la manipulación cognitiva del mundo}

La confusión y complejidad del mundo perceptible -externo e interno-, se reduce selectivamente. Algunos modos de reducción no requieren aprendizaje, como los derivados de las limitaciones estructurales, o de la adaptación (los estados constantes dejan de estimular). Otros modos de reducción son aprendidos; depende de los «modelos del mundo», representaciones no vacías, mediante las cuales se establecen comparaciones, predicciones, atribuciones de elementos a clases. Poseemos al menos tres sistemas de representación entre sí conectados: la acción (sabemos ciertas cosas porque sabemos hacerlas), las imágenes mentales y los símbolos (entre ellos el más característico es el lenguaje).

En tanto que el medio mantiene sus estímulos dentro de los patrones previstos, disminuye la alerta. La existencia de modelos permite al intelecto una mecánica de actividad a partir de evidencias parciales. Un rasgo característico de la especie humana es el de que su sistema de actividad «contiene» la posibilidad de error, la de la corrección, y la de la acomodación al error dentro de límites tolerables. Tal posibilidad es la consecuencia de la compulsiva tendencia a categorizar a partir de datos limitados. Este proceso de categorización tiene la ventaja de organizarse jerárquicamente y elabora estructuras ramificadas, las cuales contienen muchas alternativas para la acción. La categorización reduce drásticamente la necesidad de capacidad en el almacén.

Otra característica de la especie humana consiste en que la acción vicaria del pensamiento puede ser ayudada e incrementada en posibilidades mediante complementos o «amplificadores» proporcionados por la cultura. Estos amplificadores pueden ser de tres tipos: (i) amplificadores de la acción, las herramientas y los programas de acción en los que pueden insertarse las herramientas; (ii) amplificadores de los sentidos, los sistemas de señales, los diagramas, aparatos...; (iii) amplificadores de los procesos de pensamiento, modos de pensamiento, teorías, lenguajes, metalenguajes, auxiliares automáticos. 
Mejorar las condiciones de la educabilidad humana estriba, por lo dicho, también en la mejora de las estrategias de respuesta a los límites estructurales y el aumento de las competencias de manejo de instrumentos y mediadores de recepción, almacenamiento y tratamiento de información.

\section{Manipulación directa de la estructura comportamental}

Después de lo dicho anteriormente, una vía de intervención sobre el sistema neuronal, por más difícil técnicamente que sea y por más inmoral que en ocasiones pueda parecer es -de hecho- la de la intervención directa sobre el sistema neuronal. Las formas de acceso directo son muy variadas:

- Manipulaciones físicas ${ }^{9}$; (a) La psicocirugía. Hoy se encuentra en desuso por el progreso de la psicofarmacología; (b) Cirugía esteroatáxica, introducida por Spiegel y Wycis (1947), consiste en que mediante la introducción de un electrodo dirigido por rayos $\mathrm{X}$ se destruyen o estimulan eléctricamente zonas del cerebro profundo en atenuación de trastornos resistentes a los fármacos; (c) Estimulación eléctrica; (d) El telecontrol con implantación de microelectrodos lo ha empleado en animales José Manuel Rodríguez Delgado;

- Las manipulaciones químicas ${ }^{10}$. (a) El narcoanálisis: la reducción de la vigilancia lleva a la posibilidad de verbalización de experiencias que bloquean psicológicamente el psiquismo; (b) Los neurolépticos y las drogas psicotrópicas. La persona que se droga lleva a cabo una manipulación directa de su psiquismo en la que voluntariamente se expone a la pérdida de control sobre su comportamiento y a las lesiones que pudieran derivarse en la propia estructura.

- Las manipulaciones psíquicas. (a) La maleabilidad de la mente se manifiesta en las técnicas empleadas en la expansión de la moda, las técnicas de difusión de información a colectividades. Poniatowski afirmaba que se puede conseguir mediante influencias de esta naturaleza la dimisión de la mente crítica. El adoctrinamiento... (b) Toda la psicoterapia se establece y desarrolla bajo el principio de la maleabilidad de la mente y de la posibilidad cooperativa de influencia desde el exterior de un sujeto. Las técnicas psicoterapéuticas son muy variadas. (c) Los efectos psicológicos del aislamiento y de la privación sensorial. (d) El denominado lavado de cerebro que describe Solienitzin en $E l$ archipiélago Gulag.

El campo más evidente de modularidad es aquél que tiene lugar cotidianamente a partir de la actividad normal de la mente en sus relaciones con el mundo de los hombres entre las cosas. Este proceso lo denominaremos fenómeno educacional en general. No lo llamamos como Nasif educación cósmica porque sin interacción humana, o en la soledad del hombre con el mundo, aunque fuese posible la mera sobrevivencia, la actividad mental se reduce al mínimo; el producto humano en la absoluta soledad desde el nacimiento, si pudiese sobrevivir, sería antropológicamente irreconocible. No es la comuni-

9. Rodríguez Delgado, J. M. (1972), Control físico de la mente. Hacia una sociedad psicocivilizada (Ed. Espasa Calpe, Madrid), p. 89.

10. San Feliciano, M. A. (1990), Iatroquímica. La creación de sustancias para la medicina (Ed. Universidad de Salamanca). 
cación con el mundo, en cuanto tal, la que proporciona y fomenta la condición humana, sino la del mundo de la vida, la de la comunicación con las cosas y los hombres: el sistema mundo de la vida humana.

\section{Educabilidad inducida}

Después de este análisis aparecen dos consecuencias claras para el proceso de la educación y la comprensión del concepto de educabilidad: (i) que la totalidad de la arquitectura mental de un sujeto se pone en funcionamiento ordenada y plenamente con la sola relación con el medio activo e influyente y las relaciones de influencia mental propias de la existencia social; contra esta primera consecuencia solamente iría lo que se denomina la situación del niño lobo o la del aislamiento existencial, cosa que deja al ser humano si sobrevive en condiciones antropológicamente deplorables; (ii) que en la educación tiene lugar un segundo elemento que es el de la direccionalidad de muchos de los procesos mentales en el sentido de conseguir determinadas pautas comportamentales y determinados niveles de dominio de procesos en función de requerimientos sociales. Ambos tipos de aspectos de la interacción con el mundo (de las cosas y de los hombres) constituyen con propiedad procesos educacionales, aunque poseen caracteres funcionalmente diferentes y que mutuamente pueden recubrirse. De la existencia de ambos aspectos funcionales, uno imprescindible ontogenéticamente y el otro absolutamente recomendable socialmente, hemos de concluir que la educabilidad humana no se orienta teleológicamente tan sólo a la moralidad, sino que también cumple una función de activación del sistema operativo humano. En este segundo cometido funcional se fundamenta el concepto de estimulación precoz, o sobre-estimulación.

No quedan en eso las consecuencias. Por lo general el lenguaje coloquial entiende la educación como un proceso diseñado, con más o menos interés y competencia, por unos hombres (en particular adultos), sobre otros (preferentemente niños), para producir influencias (sobre todo de carácter moral). Sin embargo se puede colegir de cuanto hemos dicho que enriquecer la estimulación del medio (en el sentido acumulativo y en el sentido de transformación de la realidad que la haga más legible) es un acto educativo fundamental. Fundamental y el primero en demostrar su ventaja, dado que el patrón cooperativo es anterior al patrón linguístico. Pero dado que el medio se compone de cosas, instituciones, personas...; el cambio en el estado de cosas, el desarrollo de las instituciones y el cambio de las personas, es causalmente prioritario en los efectos educacionales a la inducción del cambio educativo mediante la palabra o la institución profesionalizada. Los más primigenios procesos de influencia educacional se encontraron asociados a la vida cotidiana y a sus cambios, a las relaciones espontáneas y a sus cambios; son más primigenios y primitivos que los roles y las agencias institucionalizadas. Estos últimos sistemas de influencia son vicarios o secundarios, respecto a los primeros, como lo prueba el hecho de su posterior aparición. Que la educación en el medio se denomine extraescolar, informal..., y la poca atención que, a veces, se le presta demuestra una laguna grave de la Teoría de la Educación, un auténtico extravismo conceptual.

La síntesis de la modulabilidad del comportamiento, junto al desarrollo de la capacidad de comunicación que permite el lenguaje y cualquier otra modalidad de relación, y al potencial de creación de entornos reales y de significado que permite la creatividad 
del hombre -personalidad, relación, situación- constituyen una tríada que vista desde la óptica del proceso de cambio en el comportamiento y de las consistencias que puede alcanzar, denominamos educación.

La educación puede considerarse, en tanto que proceso de modulación del comportamiento que adquiere consistencias (habitus), (i) desde la óptica de los procesos de influencia que producen afectación e inducción del comportamiento, (ii) o desde la óptica de los escenarios que concretan las oportunidades culturales o las posibilidades para la creación cultural.

La capacidad humana de transformación de la relación con la naturaleza en cultura no puede hacer olvidar los elementos fundamentales y obvios que explican tal capacidad, para huir demasiado rápidamente al mundo de las ideas, o a situarse en sistemas ideológicos excesivamente lejos de la corporeidad y lejanos de la naturaleza como la parte «menos noble» de nuestro entorno, cuya condición no supera la de la mera pertenencia o propiedad, escenario y campo de operaciones. En nuestras sociedades complejas la interpretación de la corporeidad -realidad y expresión-, la relación con la naturaleza -medio de vida, material simbólico y espacio vital- siguen siendo las bazas fundamentales de una buena educación, una educación que alimente la esperanza de vida, la expectativa de felicidad y comprometa a cada individuo en el futuro de todos.

\section{Visión sistémica de la educabilidad}

Hemos considerado diferentes causas que hacen posible la realidad de la educación en el hombre: de origen filogenético, de origen neurofisiológico... Nos vamos a concentrar en algunas que denominaremos sistémicas.

El proceso educacional no es meramente un proceso de cambio cualquiera en el complejo sistema orgánico humano, ya que difiere de los procesos de maduración fisiológica y del desarrollo (que también son cambios). Los procesos educacionales, además de por todo lo dicho, son posibles porque se da interdependencia funcional entre el individuo y su entorno. El principio de la interdependencia es universal en los seres vivos y el de la interdependencia con el entorno es común a todos los sistemas abiertos; sistemas que en su propia definición implican un entorno. Mejor que interdependencia sería decir interacción o interinfluencia, ya que mutuamente se influyen y modifican. Si la interdependencia entre el ser vivo y su medio (el que forman los demás individuos de su especie, el de las especies con ella conectadas tróficamente -de manera directa o indirecta-, el del resto de los componentes del nicho ecológico) es fuente de modulación evolutiva, comportamental, y de aprendizaje; las propiedades de modulación comportamental y de aprendizaje aumentan de manera sorprendente cuando los individuos -caso único de los hombres- son capaces de diseñar ambientes. La educabilidad, en tanto que posibilidad de modelamiento comportamental, no se encuentra únicamente en dependencia causal del nivel evolutivo del sistema nervioso, sino que lo está igualmente de la configuración ambiental -sobre todo de los elementos del ambiente que han sido culturalmente diseñados precisamente con la intención de promover procesos educacionales-. Sirva como ejemplo la asociación entre optar por la vida contemplativa y meterse en un convento; conseguir plena autonomía e irse de casa... 
La consecuencia más evidente de la interacción entre organismos y entornos es la diferenciación específica; la consecuencia más evidente de la interacción entre individuos y ambientes es la diferenciación cultural, la cual conlleva la variación de los procesos y de los resultados de la educación en dependencia del espacio y del tiempo.

Según ésto, tanto originará procesos configurantes (de un signo u otro) la influencia directa de unos individuos sobre otros, como la acción política que promueve unas determinadas condiciones de vida. Por lo habitual la reflexión educativa se centró sobre las acciones culturales (desde la acción de enseñar... a la acción de exhibir una obra que nos deje estéticamente complacidos); en las comunidades complejas o en las que se encuentran en vías de desarrollo, o cuando se pretende el remedio progresivo a la desigualdad existente, tiene tanta o mayor importancia la reflexión sobre políticas culturales.

La educabilidad tiene pues una vertiente -además de la orgánica e individual- la espacial y temporal. Poner como meta de la educabilidad, la perfección, es transportar la educación al campo de la metafísica, transponer la Pedagogía, ya que incluso la perfección tiene un canon o prototipo que se encarna en el tiempo y en el espacio. Finalmente, no podemos olvidar que la educación representa el grado de plasticidad y flexibilidad con el que el etograma humano posible puede satisfacer la sobrevivencia placentera, dentro de un sistema social organizado donde se distribuyen y reparten responsabilidades. Con lo que la educación y la educabilidad se encuentran conectadas en sus procesos y productos a la adquisición de habilidades profesionales. Educación sería, bajo este respecto, el proceso mediante el que habilitar a los hombres para que en este mundo nuestro se encuentre en condiciones de ganarse dignamente la vida.

El campo técnico que hemos descrito consta, por lo dicho, de al menos:

- Dinamización comunicacional (entre individuo y medio, entre individuos, entre culturas...).

- Técnicas y diseños curriculares (para la adquisición de conocimientos, habilidades...).

- Planes y proyectos de políticas culturales (locales, regionales, internacionales...).

La educación incluye un campo de objetos y procesos muy amplio. Desde el punto de vista ecológico el proceso educativo estriba en el cambio consistente (no incidental) del modo como el individuo percibe su ambiente, se relaciona con él, e interviene en él.

\section{OPTIMISMO Y PESIMISMO PEDAGÓGICO}

\section{A. Pesismo pedagógico}

Para algunos autores la educabilidad como base de una intervención sobre el hombre, es un pronóstico imaginario, no entra dentro del campo de la acción posible. Tal proyecto, o se estrella contra lo que se denomina carácter de la persona, o contra su constitución. Así dicho, no sabe uno muy bien, sin embargo, cuál es el fundamento de la convicción acerca de que la intervención pedagógica es un despropósito, por la ambigüedad de los términos «carácter»y «constitución».

No obstante, el pesimismo pedagógico ha declarado, con frecuencia, que el trabajo pedagógico es como el de Sísifo, «un piadoso engaño». Las influencias educacionales 
simplemente se suman a la dinámica impulsiva de la propia naturaleza, y entonces consiste en un lujo superfluo, un gigantesco despilfarro. Los hombres se construyen con los elementos que les proporciona el medio activo influyente en el que se encuentran socioculturalmente insertos, y no con los aportes, proclamas y sugerencias de profesionales a sueldo, cuya relación con ellos -por más que se diga- quedan sobrevolando las aguas, mientras los peces obedecen otros señuelos.

O bien se trata simplemente de un sobreañadido y vestimenta, que cubre de un barniz superficial y efímero, que no modifica el natural de los individuos, el cual se encuentra presto en todo momento a desbordarse retirando el disfraz. El señor de las moscas, de Willians Golding, dejaría claro el punto de vista. Dejados los niños educados, sueltos y a la merced de tener que luchar por la vida, se desprenden de todos los ropajes y aparecen los patrones de comportamiento artificialmente encubiertos: no está hecho el hombre más cualificado que el animal. El mamífero estaba al acecho.

El ser y el cambio de las personas acontecerían con precisión incoercible. Los cambios y transformaciones que la educación promueve ni serían permanentes, ni de efectos constantes. La educación no podría tener la pretensión de definirse como una transformación auténtica y consistente de la naturaleza humana.

Los planteamientos que contiene el pesimismo pedagógico han tenido su fundamento en la perspectiva meramente biológica del análisis del desarrollo humano. El punto de arranque sería el siguiente: dentro de la secuencia animal, en el sentido de mayor diferenciación biológica y menor especialización del comportamiento, el hombre ha sido la meta y la consumación del proceso evolutivo. «Nuestro planeta ha tenido su período de juventud y de intensa producción de formas de vida... que irremisiblemente ha terminado... ahora está en la edad madura, que ha tenido un acontecimiento notable, la aparición del hombre» (Lucien Cuénot). Pero sin dejar de ser un acontecimiento animal. Por lo tanto, dentro de esta perspectiva hay que situar la explicación de los fenómenos psíquicamente tran transcendentales como son los procesos educativos.

Allí donde persista todavía la obscuridad dentro del reino de la ciencia, hay que desconfiar, ante todo, de la obscura claridad que desciende de la metafísica. Siguiendo planteamientos de J. Rostand ${ }^{11}$, diríamos que las voluntades, intenciones y designios que el hombre propone o impone al hombre, son meramente superficiales, porque el hombre no procede de otros hombres, sino por la línea de la biología (la genética o la reacción adaptativa), todo lo demás -lo pedagógicamente inducido o culturalmente fomentado (el dinamismo civilizatorio)-, no queda propiamente incorporado a la especie, no pasa a ser propiedad radical del hombre. Los procesos educativos solamente se pueden considerar superficialmente conformantes.

Hasta es posible, siguiendo por aquí, plantear una visión pesimista de lo cultural, en el sentido de que se puede arbitrariamente considerar un comportamiento como culturalmente adecuado y valioso, aún cuando finalmente se manifieste como una invención degradante. Tómese en cuenta todo el problema de la contaminación ambiental, resultante de las aspiraciones civilizatorias de los grupos humanos. Aun cuando el éxito social pudiese atribuirse, al menos en parte, a la calidad de la inteligencia, y ésta tuviese la condición de heredable, mientras que el hombre no sea tratado siempre como hombre, 
mientras la competencia de los genes no se ejerza en condiciones relativamente leales, no podemos atribuir las diferencias manifiestas a diferencias originarias (Rostand, o. c., p. 86). Siempre, ante las inclemencias de la vida, nos quedaría el consuelo de conservar intactos nuestros cromosomas y estructuras genotípicas para vengar las injurias sociales en nuestros descendientes.

La civilización aparece, en esta perspectiva, como un añadido que, mediante la tradición o la herencia social, se transmite de unas generaciones a otras. Este fenómeno no tiene ciertamente analogía dentro del reino animal. Aunque se han observado modificaciones en los comportamientos instintivos y transmisión generacional de dichas transformaciones. El canto de los pájaros es, en parte, aprendido; en localidades diferentes una especie posee dialectos de cantos distintos; pueden mostrar preferencias alimenticias diferentes o técnicas de aprovisionamiento diferenciadas..., las cuales, en algunas especies al menos, se originan del aprendizaje e imitación de los padres.

Pero la herencia social es radicalmente distinta de la herencia biológica. Respecto a lo cultural, la generación anterior deja simplemente ofrecidas, en conjunto, las posibilidades. Estas, cada vez, deben ser internalizadas y reasumidas con esfuerzo renovado en cada ocasión y generación. Si el medio intelectual social fuera incorporado a la naturaleza, y el hombre de siglo en siglo naciera mejor adaptado y creciendo en sus cualidades éticas e intelectuales, el progreso sería indefinido y las utopías infinitamente probables. Pero la intransmisibilidad de lo adquirido es una de las certezas mejor afianzadas. Nada adquirido se inscribe en la especie, todo queda exterior y superficial, incluso por dos motivos puede convertirse en factor regresivo para la evolución: por contaminación y regresión del medio ecológico, y por contención de la selección biológica natural.

Quizás el momento decisivo en que aparece el pesimismo radical del planteamiento sea cuando se enfrenta al hecho previsible del acabamiento de la vida humana en la tierra. «Nadie de fuera vivirá la muerte del pensamiento humano, y cuando el último espíritu se extinga sobre la tierra desierta, el universo no sentirá sobre sí ni siquiera el paso de una furtiva sombra» (Rostand, o. c., p. 187).

Así concluye el libro de Jean Rostand:
«Átomo irrisorio, perdido en el cosmos inerte y desmesurado, sabe que su febril actividad no es más que un pequeño fenómeno local, efímero, sin significación y sin sentido. Sabe que sus valores no le sirven más que a él, y que, desde el punto de vista sideral, la caída de un imperio, o incluso la ruina de un ideal, no cuenta más que el hundimiento de un hormiguero bajo el pie de un paseante distraído.
De esta forma, no tendrá otro recurso más que aplicarse en olvidar la inmensidad bruta, que le aplasta y le ignora. Repudiando el vértigo estéril de lo infinito, sordo al aterrador silencio de los espacios, tratará de volverse tan incósmico como inhumano es el universo, bravamente replegado sobre sí mismo, se consagrará humildemente, terrestremente, huma- namente, a la realización de sus mezquinos designios, en los que fingirá poner la misma seriedad que si apuntaran a fines eternos».

Dentro de este tipo de planteamientos, la interpretación del fenómeno educativo, presenta los siguientes caracteres:

- Implica históricamente un esfuerzo desproporcionado respecto a los efectos conseguidos. Como si uno de los caracteres de las civilizaciones llamadas desarrolladas fuera, por virtud de sus aspiraciones (cuya necesidad, utilidad e importancia son de difícil 
justificación), dilapidar energías. Ya que, aun cuando lo que se ejecuta en la historia es algo de complejidad creciente (compárese la diferencia entre el modo de vida y los útiles necesarios para la sobrevivencia en pueblos como Samoa, la Isla de Pascua... o en las culturas que llamamos salvajes), los beneficios propiamente específicos, de mejora de la especie o del medio ecológico, para este tipo de autores -y para otros de orientación filosófica radicalmente diferente-, son claramente problemáticos: degradación del medio, proliferación de neurosis, desarrollo y desorientación de la agresividad, mala distribución de los recursos de sobrevivencia... Los efectos que más maravillan y que más energía vital consumen, dentro de este planteamiento, son precisamente los más superficiales respecto a intereses intraespecifícos de este concreto animal humano. Piénsese en los esfuerzos por la conquista del espacio.

- Correlativamente con lo anterior, el fenómeno educativo, histórica y bioespecíficamente considerado, manifiesta desorientación respecto a los objetivos primordiales de la naturaleza. Normas absolutas a las que se atribuyen valores morales y religiosos hacen proliferar o perpetuarse anomalías génicas, problematizan el control de la natalidad, o anatematizan iniciativas por las que una especie que abandonó culturalmente la selectividad natural, consiga estructurar otra norma de similar eficacia, aunque racionalizada.

- La capacidad intelectual enorme de esta especie animal que es el hombre ha colocado como metas del fenómeno educativo unas mitificaciones de origen, una sobrevaloración de secuencias vitales, y mitificaciones de transcendencia, las cuales han suplantado el puesto que, de manera inconsciente, ocupan las metas estrictamente evolutivas de las demás especies animales, las cuales, en su momento, demostraron su intrínseco valor y significado, cuando por ellas se consiguió eficazmente la misma aparición del hombre sobre la tierra.

- Tomado en su conjunto, el fenómeno educativo es radicalmente problemático, en su actual configuración y planteamiento, desde el momento en que las cualidades del grupo se miden en función de «status socio-económicos»; y las cualidades de porvenir colectivo, en forma de «nivel de vida», medido en parámetros de capacidad de consumo y producción.

Este tipo de planteamientos adolece de dos defectos fundamentales. El primero, considerar como actividad propiamente específica aquélla de origen endógeno, y que tiene como meta el propio desarrollo espontáneo de los programas genéticos del organismo; junto a aquella otra, también endógena a la especie, por la que ésta alcanza sus metas evolutivas. No queda, sin embargo, de relieve que ninguna energía biológica tiene realidad y efecto, sino en situación transaccional con el medio. Transacción que, en el caso del hombre, no se produce sólo espontáneamente, ya que el medio próximo influyente no es el medio ecológico, sino la transformación de éste en medio transformado por la cultura. Por lo mismo, podríamos afirmar que el desarrollo evolutivo humano es en parte espontáneo y codificado y en parte constructo o educativo.

Si esto es así, surge la segunda debilidad del planteamiento. Los proyectos humanos y las responsabilidades específicas, no son meras respuestas a exigencias de favorecer la dinámica del genotipo, sino que más bien, el drama de esta especie está en el proyecto cultural e institucional dentro del cual debe resolver su sobrevivencia, lo cual reconduce la perspectiva, poniendo en primer lugar el problema educativo y cultural. 


\section{B. Optimismo pedagógico}

En el otro extremo se encuentra el optimismo radical. Los propósitos educacionales pueden lograrse totalmente y en todos. Interpreta el aparente fracaso práctico en muchos individuos, indicando que no se aplicaron ni los educadores idóneos ni los procedimientos adecuados.

El fracaso educacional -es decir, la diferencia sustancial entre el sistema de comportamientos de un individuo y el que la colectividad y los educadores se propusieron-, pudiera entenderse como un error, como el fracaso de un experimento mal realizado.

El optimismo pedagógico fue un producto claro de la Ilustración. Entre uno y otro extremo se sitúa toda la reflexión pedagógica como ámbito de la racionalidad posible. La primera pregunta se refiere al hecho mismo de la posibilidad de educación en el hombre, al inmenso margen que en su comportamiento depende del aprendizaje.

\section{CONTENIDO TEÓRICO DEL CONCEPTO DE EDUCABILIDAD HUMANA}

El concepto de educabilidad contiene varios supuestos:

- Que las dotaciones genéticas con las que el hombre nace, se constituyen, y son, el soporte estructural de una gama ilimitada de comportamientos inducidos por el sistema de estímulos que componen el medio activo influyente que rodea a cada individuo.

- Que tales posibilidades de comportamiento y operaciones pueden ser sistemáticamente inducidas mediante procesos de influencia.

- Que las influencias sobre el comportamiento, cualquiera pueda ser su origen y proceso, pueden ser eficaces; es decir, pueden instituir nuevos modos de operación, producir efectos consistentes sobre el sistema de comportamientos que en cada momento define la personalidad de los sujetos. Es un clamor corriente la manifestación «has conseguido amargarme la vida», o «me hizo feliz».

- Que la realización de las posibilidades educacionales es un hecho individual y que por lo mismo, no se incorporan al código genético, teniendo que ser reactualizadas en cada nuevo individuo; no son heredables.

- Que el propio sujeto de educación, por su condición de individuo con capacidad para la elaboración de la información procedente tanto del medio externo como del medio interno, constituye una agencia de educación para sí mismo, cuyo mecanismo básico de intervención sobre sus capacidades es la práctica reflexiva, la reflexión sobre los aciertos y fracasos, durante los procesos en los que ensaya comportamientos intelectuales, afectivos o psicomotóricos.

- Que los productos originados por el perfeccionamiento de las operaciones humanas no son puramente interiores al sujeto, sino que tienen consecuencias sociales, se capitalizan para cada generación en forma de lo que se llama depósito cultural, o transformación del medio activo influyente, con lo que a la estructura que soporta el comportamiento inteligente -la cual define las posibilidades naturales-, hay que añadir la estructura y contenido del patrimonio cultural -la cual define las oportunidades sociales-. La educabilidad, pues, como ámbito de lo posible, se define dentro de un marco dialéctico o transaccional entre una y otra estructura. Ello indica que, desde un punto de vista pedagógico, la educabilidad solamente puede ser correctamente entendida dentro 
del tiempo como marco de referencia. Del tiempo que marca el desarrollo de la estructura biopsicológica, y del tiempo que marca el contexto histórico-social en el que se desenvuelven los individuos.

La categoría temporal, en su referente personal, en tanto condicionante de las posibilidades de operación, puede tener dos sentidos. El tiempo en tanto que instante y el tiempo en tanto que historia vivida. Para el Psicoanálisis, por ejemplo, la posibilidad comportamental en un momento dado, para un individuo, es función temporal de su historia vivida -en la cual adquieren particular relevancia los momentos infantiles-. Para otras corrientes psicológicas, el comportamiento es función total, lo que quiere decir que puede ser explicado en función únicamente de la personalidad (sistema actual de disponibilidades comportamentales) y del espacio vital.

Sobre estos supuestos se edifican todos los planteamientos teóricos de la Pedagogía y todas las secuencias prácticas del fenómeno educacional en su vertiente personal, interpersonal y sociocultural. De ahí la consecuencia que obtenían los pedagogos del siglo XIX, al afirmar que la educabilidad constituía el objeto formal de la Pedagogía. 